\title{
Perceptions and Receptivity of Nonspousal Family Support: A Mixed Methods Study of Psychological Distress Among Older, Church-Going African American Men
}

Journal of Mixed Methods Research 2017, Vol. II (4) 487-509 (C) The Author(s) 2015 Reprints and permissions: sagepub.com/journalsPermissions.nav DOI: I0.1 I77//5586898I5622707 journals.sagepub.com/home/mmr

\author{
Daphne C. Watkins', Tracy Wharton', Jamie A. Mitchell', \\ Niki Matusko', and Helen C. Kales'
}

\begin{abstract}
The purpose of this study was to explore the role of nonspousal family support on mental health among older, church-going African American men. The mixed methods objective was to employ a design that used existing qualitative and quantitative data to explore the interpretive context within which social and cultural experiences occur. Qualitative data $(n=21)$ were used to build a conceptual model that was tested using quantitative data $(n=40 \mathrm{I})$. Confirmatory factor analysis indicated an inverse association between nonspousal family support and distress. The comparative fit index, Tucker-Lewis fit index, and root mean square error of approximation indicated good model fit. This study offers unique methodological approaches to using existing, complementary data sources to understand the health of African American men.
\end{abstract}

\section{Keywords}

African American men, church, nonspousal family support, mental health outcomes, mixed methods

As the popularity of mixed methods continues to grow, more disciplines are beginning to expand on how mixed methods research can be used to achieve discipline-specific research goals and objectives (Curry \& Nunez-Smith, 2015; Haight \& Bidwell, 2015; Watkins \& Gioia, 2015). The distinct characteristics and utility of mixed methods research in providing depth and breadth of a research topic are attractive to both novice and seasoned scholars. First, mixed methods involve the collection and analysis of qualitative and quantitative data in ways that are rigorous and

\footnotetext{
'University of Michigan, Ann Arbor, MI, USA

${ }^{2}$ University of Central Florida, Orlando, FL, USA
}

\section{Corresponding Author:}

Daphne C. Watkins, School of Social Work and School of Medicine, Department of Psychiatry, University of Michigan, 1080 South University Avenue No. 60, Ann Arbor, MI 48I09-I 106, USA.

Email: daphnew@umich.edu 
epistemologically sound (Creswell, 2015; Creswell \& Plano Clark, 2011; Hesse-Biber, 2010; Johnson, Onwuegbuzie, \& Turner, 2007). Rigorous data collection and analysis refer to making data collection and analysis decisions that are thorough and based on a predetermined and tested system. Ensuring that the methods are epistemologically sound refers to data collection and analysis that are framed so that they help determine how we gain knowledge of what we know.

Mixed methods also involve the integration of qualitative and quantitative data in ways that underscore the advantages of using both research approaches to illuminate and advance our understanding of the topic of interest. Though it is sometimes difficult to locate studies where the methods are truly integrated, all mixed methods studies, by definition, imply some form of integration of the data (Bazeley, 2009; Creswell \& Plano Clark, 2011). Literature suggests that the type and level of integration are subject to continuing controversy (Creswell \& Tashakkori, 2007). The current study relies on the premise and promise of mixed methods research as a way to examine the breadth and depth of nonspousal family support experiences of older, churchgoing African American men. Previous scholars have used mixed methods to understand various experiences of African American men including those of male athletes at historically Black colleges and universities (Cooper \& Hall, 2014) and those of substance-abusing men who have sex with men (Buttram \& Kurtz, 2015). However, no study to date has benefited from the use and integration of qualitative and quantitative data in order to understand the nonspousal family support experiences of church-going African American men, which is the aim of this study.

\section{African American Men's Mental Health}

Findings from research on African American men's mental health underscore the importance of understanding how social (e.g., interpersonal and intrapersonal relationships) and cultural experiences (e.g., familiarities associated with being both African American and male) influence their mental health status over the adult life course (Watkins, 2012a). Several lines of evidence suggest that early exposure to disadvantaged socioeconomic conditions adversely affects the mental health of African American males, increasing risk factors for the development of psychiatric mood disorders in adulthood (Caldwell, Antonakos, Tsuchiya, Assari, \& De Loney, 2013; Ellis, Caldwell, Assari, \& De Loney, 2014). Our own research and that of others finds that in addition to the social and economic hardships many African American men face, marginalized roles within their families, communities, and society at large also restrict their ability to establish and maintain positive mental health and well-being as they age (Roy \& Dyson, 2010; Watkins \& Neighbors, 2012).

Disproportionately high unemployment and overrepresentation in low-wage occupationseven among college-educated African American men (Watkins, 2012a; Watkins \& Neighbors, 2012) - severely disadvantage access to material resources necessary to support one's self, a partner, and/or children. These disadvantages also create role strain between poor socioeconomic circumstances and the masculine social expectation for adult African American men to be providers for their families (Harris, 2013). When evaluating the adult life course of African American men, prior research reports that their mental health during middle adulthood is heavily influenced by work-related stress, interpersonal relationships, and decisions that affect their economic and social capital (Lincoln, Taylor, Watkins, \& Chatters, 2011; Watkins, Hudson, Caldwell, Siefert, \& Jackson, 2011). However, life concerns that shape mental health trajectories for older African American men shift toward adjusting to and coping with functional limitations, health-related challenges, costs associated with aging, and life transitions related to leaving the workforce such as fixed incomes and social isolation (Watkins, 2012a).

While ample research has been developed around the differential receipt of mental health services between older African Americans and Whites more broadly (Conner et al., 2010; 
Neighbors et al., 2008; Shellman, Granara, \& Rosengarten, 2011), we know surprisingly little about the social and cultural contexts of maintaining mental health throughout life transitions for older African American men. Interpersonal and family relationships take on renewed importance as people age, and since older African American men are more likely than their younger counterparts to attend church where they might receive adjuvant mental health care (Taylor, Chatters, \& Jackson, 2007), a first step in this effort is understanding the nonspousal family support experienced by older African American men who attend church. The current study extends existing literature by attempting to contextualize how nonspousal family support influences mental health outcomes among older, church-going African American men.

\section{Church Support for African American Men}

African American religious institutions have a long and varied history of providing lay mental health support for African American older adults, particularly those who live in communities underserved by formal mental health services (Chatters, Taylor, Woodward, \& Nicklett, 2015; Krause, 2006; Neighbors, Musick, \& Williams, 1998; Taylor, Ellison, Chatters, Levin, \& Lincoln, 2000). Many African Americans use faith communities, churches in particular, as a buffer for their mental health. Specifically, social support provided by a close-knit network of cocongregants is protective against psychological distress, independent of family-based social support (Chatters et al., 2015). This experience may be gendered as African American women tend to thrive in the social culture of church, at least initially, easier than African American men. Thus, African American men may not be able to benefit from the advantages experienced from the social support and, thereby, improved mental health in the context of the church compared to their female counterparts. These considerations imply that researchers and practitioners should be more deeply concerned with investigating the potential role of the church or faithbased community as a backdrop for reaching older African American men with resources that may attenuate poor mental health outcomes.

\section{Family Support for African American Men}

Research suggests that African American home life is broadly centered on a large network of kinship and family support (i.e., spouses or significant others, cousins, uncles, aunts, and close family friends; White, 2004). The social support provided by these kinship networks may look characteristically different for some African Americans compared to Whites. For example, a study by Rosenfarb, Bellack, and Aziz (2006) found that high levels of critically engaged behaviors by family members predicted better mental health outcomes for African Americans when compared to Whites. Specifically, the authors identified fervent communication styles as a common cultural practice among many African American families because approaching a family member to address problematic health behavior is viewed as an expression of concern and care (Taylor, Forsythe-Brown, Taylor, \& Chatters, 2014). Thereby, one way to understand the association between health and family dynamics among African Americans is to explicitly link multiple inquiries about one's health and well-being with the degree to which someone is concerned about that family member. A positive outcome would be for the person in question to engage in healthy behaviors as a result of the family member's concerns.

Studies have suggested that social support derived from strong family relationships has health-promoting effects for African American adults across a range of physical and mental health conditions including, but not limited to, the risk of suicide (Compton, Thompson, \& Kaslow, 2005), diabetes self-management (Tang, Brown, Funnell, \& Anderson, 2008), and cancer survivorship (Hamilton, Moore, Powe, Agarwal, \& Martin, 2010). For African American 
men specifically, marriage is an important source of health-enhancing support. In fact, a body of evidence suggests that marriage is more psychologically beneficial for African American men than African American women (e.g., Sitgraves, 2008), such that separated and divorced African American men have higher rates of depression than their married counterparts. Furthermore, relative rates of psychiatric disorder are higher in separated/divorced and never-married African American men compared with nonmarried African American women (Hurt, 2012; Sitgraves, 2008). Research characterizing the influence of familial support on health outcomes for African American men outside of spousal support is limited and mixed. However, what we know is that African American men use informal social support resources, such as family and friends, as buffers to reduce the effects of stress and distress on their mental health (Chatters et al., 2015; Pearlin, 1999; Taylor, Chatters, \& Jackson, 1997).

\section{Rationale for the Current Study}

Investigations into the social support networks of African American men and the impact of that support on physical and mental health outcomes have narrowly focused on socially marginalized men, such as those implanted in gang activity (Mac an Ghaill, 1994), the criminal justice system (Gaines, 2007), homelessness (Littrell \& Beck, 2001), and low-income nonresidential fathers (Anderson, Kohler, \& Letiecq, 2005). This shortcoming in the literature highlights the critical need to further examine how kinship and related social support can serve as protective factors for the mental health of African American men. Similarly, the research on nonspousal family support for older African American men is limited, likely due to the short life expectancy of African American men compared to African American women, 71.8 versus 78, respectively (Hoyert \& Xu, 2012). Still lower than the life expectancy for White men (76.5), the life expectancy for African American men has seen modular increases over the years, suggesting a potential "healthy survivor effect" (Lincoln et al., 2011; Watkins et al., 2011) for those who are able to maintain good health and prevent disease. These gradual increases have not received much attention, though some scholars have examined facilitators that may not only increase life expectancy but also improve quality of life for African American men.

One facilitator that has had an important role in the development of healthy African American communities has been the role of the church in the African American community, also known as the "Black church" (Dessio et al., 2004; Taylor \& Chatters, 2011; Taylor et al., 2000). For many predominately African American communities, the church has not only offered a place for spiritual healing and rejuvenation but also provided mental and physical health programs to improve and maintain the well-being of its members (Chatters et al., 2015). Both kinship networks and the church, broadly defined, are important sources of health-enhancing support for African Americans. Given the lack of evidence on how nonspousal familial support and the church (as a context) intersect to promote mental and emotional health among African American men, the current study examines the social and contextual experiences of older, church-going African American men and the role of nonspousal family support on their mental health (i.e., distress). We achieve our study goals by implementing a mixed methods design that uses existing qualitative and quantitative data sources to explore issues relevant to the interpretive context within which the social and cultural experiences of distress in older African American men takes place.

\section{Method}

\section{Study Design}

A modified exploratory sequential design (Creswell, 2015) was used to guide the study's framework and analysis. The study design involved two types of data collected for different primary 
purposes with the intent to (a) represent different levels (and types) of analysis for the same phenomenon under study and (b) form an overall interpretation of the phenomenon by uncovering concepts from the qualitative methods that can be tested using the quantitative methods (Creswell, 2015; Creswell \& Plano Clark, 2011; Kartalova-O’Doherty \& Doherty, 2009; Tashakkori \& Teddlie, 2003). We used focus group data on depression and distress from churchgoing African American men $(n=21) 50$ years of age and older in southeastern Michigan and complex sample survey data from church-going African American men $(n=401) 50$ years of age and older from the National Survey of American Life (NSAL) to build and test a conceptual model about whether (and how) older African American men perceive and receive nonspousal family support and how this support influences their psychological distress.

Qualitative Sample. The Depression Care in African American Church Elders study, or the "Churches study," is a qualitative study conducted in 2011 with African American male and female elders at predominately black churches in southeastern Michigan. The purpose of the original study was to examine the role of patient beliefs, attitudes, and other factors related to adherence to depression treatments among African American men and women. The focus group participants were asked about their experiences with depression, their perceptions of depression treatments including antidepressants, reasons for not wanting formal treatment for their depression, barriers to depression treatment, and the role of personal beliefs in relation to depression care. Three focus groups (each) were conducted with African American men $(n=21)$ and women $(n=29)$ in predominately black churches in southeastern Michigan. The current study only used the focus groups conducted with the men, for the purpose of addressing the unique needs of an aging and marginalized sample of African American men that has traditionally been understudied and underrepresented in studies on mental and emotional health. Characteristics of the African American men from the Churches study participants are presented in Table 1.

Quantitative Sample. The NSAL is the most comprehensive and detailed study of mental disorders and the mental health of Americans of African descent ever completed (Jackson et al., 2004). The NSAL is part of a National Institute of Mental Health Collaborative Psychiatric Epidemiology Surveys initiative that includes three nationally representative surveys: the NSAL, the National Comorbidity Survey Replication, and the National Latino and Asian American Study. The NSAL is designed to explore intra- and intergroup racial and ethnic differences in mental disorders, psychological distress, and informal and formal service use, as they manifest in the context of a variety of stressors, risk and resilience factors, and coping resources among national adult and adolescent samples.

The NSAL is a household probability sample of 3,570 African Americans, 1,621 Blacks of Caribbean descent, and 891 non-Hispanic Whites, aged 18 and older. The African American sample, the core sample of the NSAL, is a nationally representative sample of households located in 48 states with at least one Black adult 18 years or older who did not identify ancestral ties to the Caribbean. Most of the interviews were conducted face-to-face using a computerassisted instrument. About $14 \%$ were conducted either entirely or partially by telephone. The final overall response rate was $72.3 \%$. Data were collected between February 2001 and March 2003 using a stratified and clustered sample design. Weights were created to account for unequal probabilities of selection, nonresponse, and poststratification, all of which make NSAL a complex sample survey. The current study focused on the 401 African American men 50 years and older who reported that they attended church. Table 2 presents characteristics of NSAL study participants. 
Table I. African American Men: Churches Study Participants $(N=21)$.

\begin{tabular}{|c|c|c|}
\hline & $N$ & $\%$ \\
\hline Age range & \multicolumn{2}{|c|}{$50-87$ years } \\
\hline Years of education & \multicolumn{2}{|c|}{$6-18$ years } \\
\hline Involvement in church & & \\
\hline Staff & 7 & 33 \\
\hline Member & 17 & 81 \\
\hline Chairperson/frequent volunteer & 5 & 24 \\
\hline Regular attendee & 12 & 21 \\
\hline Not reported & I & 5 \\
\hline \multicolumn{3}{|l|}{ Emotional health } \\
\hline Excellent & 3 & 14 \\
\hline Very good & 6 & 29 \\
\hline Good & 9 & 43 \\
\hline Far & 2 & 10 \\
\hline \multicolumn{3}{|l|}{ Income, \$ } \\
\hline$<20,000$ & 3 & 15 \\
\hline $20,001-30,000$ & 3 & 14 \\
\hline $30,001-40,000$ & 6 & 29 \\
\hline $40,001-50,000$ & 4 & 19 \\
\hline $50,001-60,000$ & 3 & 14 \\
\hline$>60,000$ & 2 & 10 \\
\hline
\end{tabular}

Table 2. African American Men: NSAL Respondents Who Reported Attending Church $(n=40 \mathrm{I})$.

\begin{tabular}{lrr}
\hline & $N$ & $\%$ \\
\hline Age-group, years & & \\
$50-59$ & 186 & 48 \\
$60-69$ & 119 & 29 \\
$\geq 70$ & 96 & 23 \\
Health insurance (yes) & 340 & 88 \\
Education level, years & & 36 \\
$<11$ & 161 & 28 \\
I2 & 110 & 18 \\
I3-I5 & 68 & 18 \\
$>15$ & 62 & 47 \\
Employment status & & 4 \\
Not in workforce & 197 & 49 \\
Unemployed & 13 & \\
Employed & 187 & 36 \\
Marital status & & 3 \\
Married & 179 & 33 \\
Partner & 11 & \\
Separated & 169 & 36 \\
Never married & 39 & 21 \\
Poverty index & & 33 \\
I & 70 & 30 \\
2 & 96 & 127 \\
3 & 108 & \\
4 & & \\
\hline
\end{tabular}

Note. NSAL = National Survey of American Life. Average household income was $\$ 43,874$.

${ }^{a}$ Poverty status measured categorically in relation to poverty thresholds; I = poor, with percentage of the poverty line of $<100 \%$; $2=$ near-poor, with percentage of the poverty line of $\geq 100 \%$ to $199 \%$; $3=$ nonpoor, with percentage of the poverty line of $\geq 200 \%$ to $399 \%$; and $4=$ nonpoor, with percentage of the poverty line of $\geq 400 \%$ (National Center for Health Statistics, 1998). 


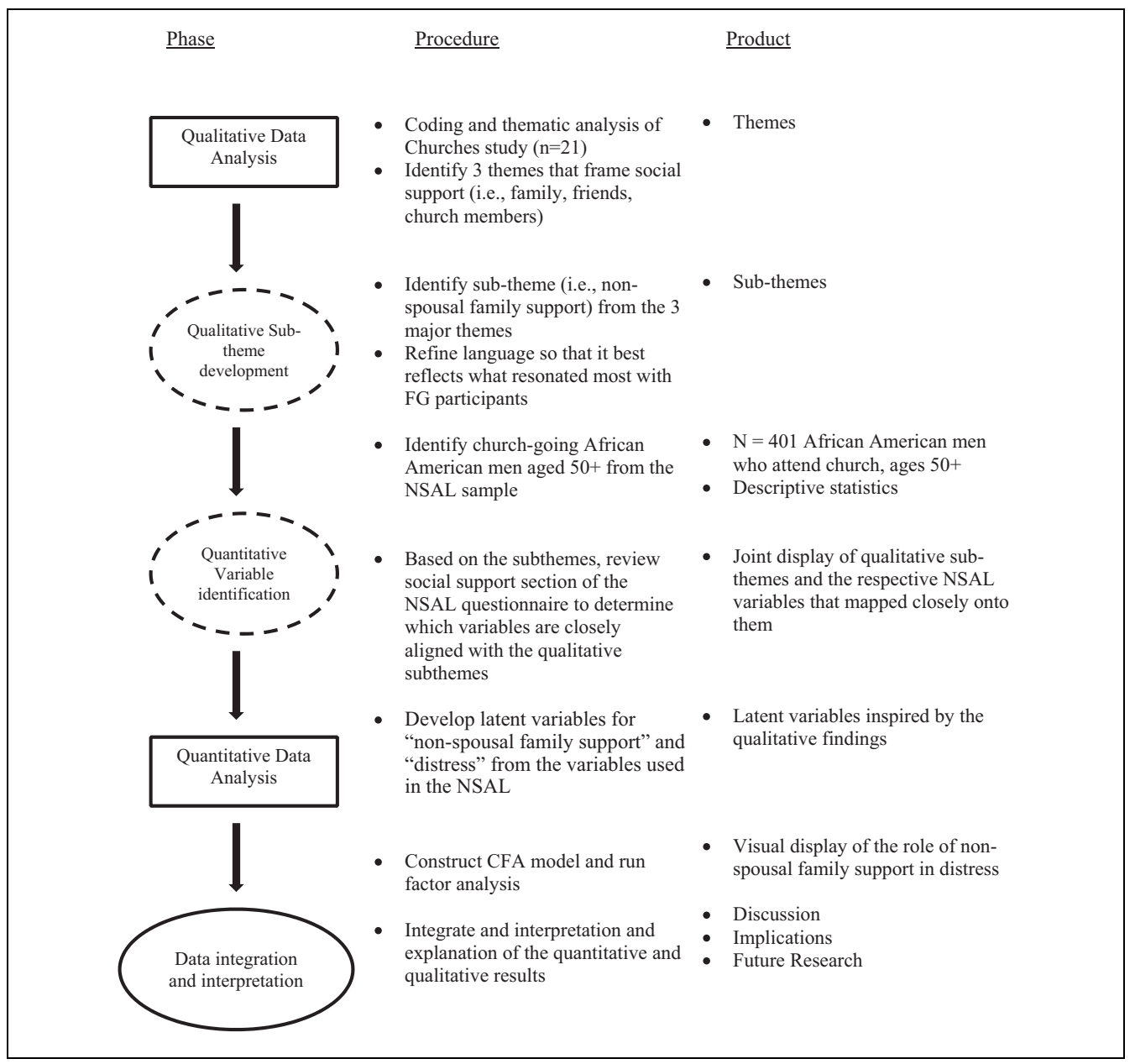

Figure I. Procedural diagram for the modified exploratory sequential design procedures. Note. $\mathrm{FG}=$ focus group; NSAL = National Survey of American Life; CFA = confirmatory factor analysis.

\section{Procedure}

We implemented our "modified" exploratory sequential design using existing data (Figure 1), which involved analyzing the qualitative data first and then analyzing the quantitative data. We are coining the term for the type of mixed methods design we implemented ("modified exploratory sequential design") because our use of existing data meant that we did not need to collect any original data in order to complete the steps for our mixed methods study. First, in the qualitative phase of the study, we identified family support concepts derived from the church-going African American men 50 years and older from the Churches study. Those data were coded and analyzed, which resulted in themes that helped in understanding phenomena relevant to three types of social support (i.e., family, friends, church members) for older, church-going African American men. Our qualitative analysis included sensitivity to important cultural norms and idioms for the older, church-going African American men in our study.

Family support, friend support, and church member support were all robust themes within themselves, each possessing multiple layers and code hierarchies. Therefore, we decided to delve deeper into each of the support themes, beginning with family support (which is the focus 
of this study) in order to fully understand how each is experienced by African American men in the Churches study. Our more focused analysis of the family support theme resulted in a number of subthemes - primarily a differentiation between family defined as either (a) spouses/significant others or (b) nonspouses/significant others. Especially piqued by the support offered by those who were not spouses and significant others, we decided to further investigate this subtheme in the older, church-going African American male sample, and to refine the language of our subthemes so that it best reflected what resonated most with the Churches study focus group participants.

Framing our procedures in the context of the knowledge level continuum (Grinnell \& Unrau, 2014) meant that we tested the conceptual model built using the qualitative Churches study data with the quantitative NSAL data. Specifically, after identifying the nonspousal family support subtheme and respective concepts from the Churches study, we built a conceptual model of nonspousal family support. For the purposes of this study, and our desire to expound on the nonspousal family support networks of older, church-going African American men, we narrowed in on the concepts that emerged from the interpersonal level and included the respondents' family history, group identification, and social norms. Social support from nonspousal family members has been identified as vital among African American men as, oftentimes, some of them go to a friend or family member for their problems and do not seek more formal, professional help. This context was the foundation up on which we built our exploratory sequential design using existing data.

After identifying nonspousal family support concepts from the Churches study, we reviewed the social support section of the NSAL questionnaire to determine which variables are the most closely aligned with the qualitative subtheme, nonspousal family support. Then we generated a list of social support variables from the NSAL that were aligned with nonspousal family support, and developed latent variables for both nonspousal family support and distress using measures from the NSAL. Finally, we performed a confirmatory factor analysis, integrated the qualitative and quantitative data, and then interpreted the mixed methods findings as they related to the role of nonspousal family support in distress for older, church-going African American men.

Qualitative Data Management and Analysis. The qualitative analysis was guided by a team approach (Watkins, 2012b; Watkins \& Gioia, 2015) supervised by the lead author. The study team used a spreadsheet technique to organize, manage, and analyze the data (Stockdale, 2002; Swallow, Newton, \& Lottum, 2003). First, a word processing program was used to place all of the data into a table with multiple rows and columns. The development of this spreadsheet, or "all-inclusive data table," was the first step in the analysis process. The data table included seven column headings: transcript number, questionnaire section, question asked, participant's response, notes, code, and theme. After this data table was created, the team used a data reduction technique developed by the lead author called the "rigorous and accelerated data reduction" (RADaR) technique for qualitative data analysis (Watkins \& Gioia, 2015).

The purpose of the RADaR technique is to reduce the qualitative data in a way that generates results quickly and rigorously for translation and dissemination to intended audiences. The RADaR technique is implemented using a team-based analysis approach (Fernald \& Duclos, 2005; Guest \& MacQueen, 2008; Watkins, 2012b; Watkins \& Gioia, 2015), and was developed for the purpose of analyzing various types (e.g., focus groups, interviews, case studies, existing documents, etc.) and quantities (e.g., 5 case studies, 12 individual interviews, 8 focus groups, etc.) of qualitative data to efficiently generate results that can be incorporated into specific project deliverables. Project deliverables can range from peer-reviewed articles for scientific journals to a thesis, dissertation, final report, conference presentation, book chapter, and/or health promotion materials. For the purposes of this study, the project deliverable was a manuscript that would report the findings from the guiding question: "What are the social and cultural 
experiences of nonspousal family support for older, church-going African American men who experience psychological distress?"

Before beginning the RADaR technique, analysts should have already completed some of the preliminary, preparatory steps for team-based qualitative data analyses that have been described elsewhere (Fernald \& Duclos, 2005; Guest \& MacQueen, 2008; Padgett, 2008; Watkins, 2012b; Watkins \& Gioia, 2015). The nature of the RADaR technique implies that it should be used as a tool for-and in conjunction with - completing other steps in team-based qualitative analysis. For example, the RADaR technique can be implemented after the team revisits the research question and becomes "one" with the data (Taylor-Powell \& Renner, 2003; Watkins, 2012b) but before the team develops the data's "open codes" (Grinnell \& Unrau, 2014; Ulin, Robinson, \& Tolley, 2005; Watkins, 2012b). Tables and spreadsheets developed in word processing, and accompanying general-purpose computer programs (Niglas, 2007; Stockdale, 2002; Swallow et al., 2003), are the bases for the RADaR technique, as they tend to encourage the analyst to focus more on the content of the data and less on the bells and whistles that qualitative data analysis software packages have to offer.

For this study, the data tables underwent four reduction phases, and each signified a more narrow and specific presentation of the qualitative data. The RADaR technique used for the present study involved first producing an all-inclusive data table. Then, to reduce the qualitative data, the study team reviewed the all-inclusive data table and made notes about areas of commonality and overlap across groups or between participants (e.g., transcript numbers, church groups), and then generated notes about the relevance of certain quotes and the intersection of concepts. As a part of the data reduction process, coding procedures were employed that allowed segments of raw text to be identified and compared to other segments, and analyzed for embedded meaning. A two-level coding process was employed. The first level of coding (i.e., open coding) identified preliminary text segments that were used to identify categories, concepts, and themes germane to the overall project goals and objectives. During this level of coding, data were analyzed using classical content analysis, which involved identifying the frequency of codes to determine which concepts were most cited throughout the data (Leech \& Onwuegbuzie, 2008; Watkins, 2012b).

Informal support networks, and the subcodes therein (e.g., church, family, and friends), were identified as "open" codes that required further analysis. In other words, the informal support network codes were so robust that they each required additional analyses. Thus, a more "focused" level of coding (Grinnell \& Unrau, 2014; Watkins, 2012b) was used to examine each subcode, beginning with family support networks, the focus of the current study. Once our analysis team delved deeper into family support networks, we identified both spousal and nonspousal family support constructs. Concepts and categories derived from nonspousal family support were rich in social and cultural contexts, so the team used constant comparative analysis to generate a theory, or set of concepts (Leech \& Onwuegbuzie, 2007) that further elaborated on the nonspousal family support networks of older, church-going African American men. The purpose of this level of the analysis was to acquire a deeper understanding of the nonspousal family support experiences of the Churches study participants. The analysis team worked individually and then collectively to "reduce" and code the data. These concepts were then mapped onto the NSAL questionnaire items and analyzed quantitatively, as described below.

\section{Quantitative Measures and Analysis}

Measures. Our mental health outcome for the quantitative phase of the study was psychological distress and was measured using the Kessler-6 (K6). This is a six-item scale designed to assess nonspecific psychological distress, including symptoms of depression and anxiety in the 
past 30 days (Kessler et al., 2010). The K6 is intended to identify persons with mental health problems severe enough to cause moderate to serious impairment in social and occupational functioning and to require treatment. Each item is measured on a 5-point Likert-type scale ranging from 0 (none of the time) to 4 (all of the time). For our analysis, positive valence items were reverse coded and summed scores ranged from 0 to 24, with higher scores reflecting higher levels of psychological distress $(M=3.37, S E=0.18$; Cronbach's $\alpha=.81)$. In the psychological distress scale of the NSAL questionnaire a seventh item, borrowed from the Center for Epidemiological Study-Depression scale (i.e., feeling "blue") was listed, so we included this in our psychological distress measure. The results of our exploratory factor analysis indicated that all items loaded well onto a single latent factor with all factor loadings above 0.7.

We then created a latent variable, called nonspousal family support, using six factor items that described the behaviors of the Churches study respondents and their feelings toward their nonspousal members. The six items were labeled help, communication, closeness, feeling loved, listening, and expressing interests/concern. "Help" was assessed with the question "How often do people in your family - including children, grandparents, aunts, uncles, in-laws, and so onhelp you out?" "Communication" was assessed with the question "How often do you see, write, or talk on the telephone with family or relatives who do not live with you?" "Closeness" was assessed with the question "How close do you feel toward your family members?" These three questions were individual items from the NSAL questionnaire. "Feeling loved," "listening," and "expressing interest/concern" were measured using three individual items where respondents were asked, "Other than your (spouse/partner) how often do your family members: (a) make you feel loved and cared for, (b) listen to you talk about your private problems and concerns, and (c) express interest and concern in your well-being?" Response categories ranged from "very often" to "never," with higher values on this index indicating higher levels of support. Cronbach's alpha for this six-item index was .77. Additionally, the results of the exploratory factor analysis supported a single latent factor solution with all factor loadings above .6 .

Data analysis. The NSAL includes 1,217 African American men. Of these, 401 identified as church-going, African American men 50 years and older, and in our analyses we examined the psychological distress outcomes of these men. All analyses were weighted to be nationally representative of the populations and subgroups of interest and were conducted using STATA 13 (StataCorp, 2013). Additional analyses involved measuring the relationship between the latent, nonspousal family support variable and the pervasiveness of psychological distress for the older African American men in the sample. The means and percentages represented weighted proportions based on the sample's race-adjusted weight measure, and the standard errors reflected the recalculation of variance using the NSAL's complex design. There were small amounts of missing data (occurring sporadically and never exceeding more than $4 \%$ of the cases for all key study variables), therefore listwise deletion was used. The data were slightly skewed but less than an absolute value of 2 . The estimation method used was maximum likelihood estimation with robust errors.

We conducted confirmatory factor analysis via SVY SEM in STATA 13 to examine the factor structure and replicate previous studies that have discussed the influence of family support on mental health outcomes across church-going, African American male respondents 50 years or older using the NSAL (Lincoln, Chatters, \& Taylor, 2003). Using the conceptual model we created with the qualitative findings from the Churches study, we hypothesized that help, communication, closeness, feeling loved, listening, and expressing interests/concern will measure the latent construct "nonspousal family support," and the seven items in our psychological distress scale will measure the latent construct "psychological distress" in the NSAL.

The overall fit of each construct was evaluated using multiple indicators of model fit: chisquare, the comparative fit index (CFI), the root mean square error of approximation (RMSEA), 
Table 3. Churches Study Qualitative Themes and Subthemes for Nonspousal Family Support.

\begin{tabular}{|c|c|}
\hline Themes & Subthemes \\
\hline $\begin{array}{l}\text { 1. African American men have a } \\
\text { distress management } \\
\text { "process." } \\
\text { 2. Nonspousal family members } \\
\text { are a part of the distress } \\
\text { management "process" used } \\
\text { by African American men. } \\
\text { 3. African American men expect } \\
\text { assistance and support from } \\
\text { their nonspousal family } \\
\text { members. }\end{array}$ & $\begin{array}{l}\text { - Siblings, children, and extended family help frequently. } \\
\text { - African American men often communicate with family members, } \\
\text { and reach out to family whenever they need help. } \\
\text { - African American men feel close enough to family members } \\
\text { to go to them with their mental health problems. } \\
\text { - African American men feel emotionally supported by family } \\
\text { members regarding their mental health needs. } \\
\text { - African American men's family members listen to them; they } \\
\text { feel connected to family members. } \\
\text { - African American men's family members appear interested in } \\
\text { their mental health needs and overall well-being. }\end{array}$ \\
\hline
\end{tabular}

and the Tucker-Lewis index (TLI). The chi-square statistic was used to assess the sample and implied covariance matrix; a good fitting model is indicated by a nonsignificant result. The CFI (Bentler, 1990) along with TLI (Tucker \& Lewis, 1973) are measures for how much better the model fits the data compared to a baseline model where all variables are uncorrelated. For these indices, values above .90 indicate reasonable fit while values more than .95 indicated good model fit (Hu \& Bentler, 1999). Values close to 0.08 or below for the RMSEA represent acceptable model fit. In addition, we used the standardized root mean square residual (SRMR; Jöreskog \& Sörbom, 1981) to determine good model fit. Ideally the SRMR should be less than .05 , though values less than .08 also indicate an adequate fit (Hu \& Bentler, 1999). Finally, we used the Akaike information criterion (AIC; Akaike, 1974) to evaluate the alternative models, with smaller values indicating a best fitting model. Based on the models in this study, we could load items only onto a single factor, with uncorrelated measurement error terms as suggested in previous research (Boduszek, Shevlin, Mallett, Hyland, \& O'Kane, 2012).

\section{Results}

\section{Qualitative Findings}

Three overarching themes were apparent during our analysis of the nonspousal family support concept, with regard to distress, in the Churches data (Table 3). In particular, focus group respondents noted that (a) they have their own processes for managing their distress, (b) their nonspousal family members were included in these processes, and (c) they depend on their nonspousal family members to support them when they experienced psychological distress. First, when participants were asked what they would do if they needed help with a mental health problem, many of them provided a sequence of steps they would follow. Specifically, many respondents noted that they would not seek professional help because they have their own processes that they undergo. These processes were oftentimes implemented when dealing with depression and/or distress, and for many participants, it began with praying and/or trying to resolve the problem on their own, prior to seeking help from a family member. Several of the focus group respondents noted that these processes were specific to (and in the context of) their families and their church. One participant noted,

I think, the first thing I would do myself is try to find out what is the problem, why are you there, you know, why are you locked up in this? Stuck? Why are you stuck here, you know, what's going on ... 
When probed to talk more about the influence of their family members in their help-seeking behaviors, some of the men spoke about family more generally, while others identified specific members of their family who were particularly helpful. According to the participants, these family members were more likely to be the people they would talk to about their distress and other mental health challenges.

The second theme that emerged from the data was that nonspousal family members were intimately involved in the processes for dealing with distress. After first trying to solve the problem on their own, then seeking assistance from their spouses, the men noted that their nonspousal family members were often their third line of defense. Specifically, they discussed the importance of being able to talk to family members who know them and who know and understand their mental health history. Beyond spouses and female partners ("I would go to my wife. She's the one with me more than anyone else"), the participants discussed the availability of other family members, included their siblings and children. For example, one participant said, "I would go to my sister who has been with me from the beginning," while another stated,

Well I'd go to my daughter. I have a daughter with me, my consolation. I don't have no sister or brothers.

During our analysis, we also noted that when the participants spoke about seeking assistance from their siblings for a mental health problem, they primarily discussed going to their sisters but not their brothers.

The final theme that emerged from the Churches study involved how dependent the participants were on their nonspousal family members regarding their mental health and well-being. Participants agreed that despite stereotypes of African American men, they, themselves, depend heavily on the assistance and support of their family members, particularly when dealing with distress. One participant noted that his son is particularly helpful.

If my son tells me, "Dad, I think you ought to go to the doctor" I go, because I can get hardheaded sometime and tough ... so yes, [he does] influence it.

During our expansion of this theme, we noted that the men spoke freely about welcoming assistance from their nonspousal family member during difficult times, which for them occurred at various points throughout their lives. The men spoke honestly about their blemished pasts, noting that despite the ups and downs they had experienced over the course of their lives, they marked their entry (or, for some, their return) to the church in their later years as a positive turning point in their mental health and overall well-being. The overwhelming majority of the participants in our focus groups expressed a sense of belonging and support from their church "family," often referring to one another as "brothers," though there were no biological relationships confirmed between them and other male church members.

\section{Quantitative Findings}

After exploring the nonspousal family support experiences of the Churches study participants, the NSAL data were used to complement our qualitative findings by examine nonspousal family support and distress using a representative sample of older, church-going African American men. Our analysis of the NSAL data included a total of 401 church-going African American men 50 years and older. We included sociodemographic measures such as household income (using the poverty index from the National Center for Health Statistics, 1998), education, employment status, and marital status. These and other demographic 
Table 4. Coefficients for the Structural Model and Measurement Model.

\begin{tabular}{lcccc}
\hline & Coefficient & $S E$ & $t$ & $p$ \\
\hline $\begin{array}{l}\text { Measurement model } \\
\text { Nonspousal family support }\end{array}$ & & & & \\
$\quad$ Help & 1 & & & \\
Communicate & 0.60 & 0.04 & 15.08 & $<.001$ \\
Closeness & 0.86 & 0.05 & 16.31 & $<.001$ \\
$\quad$ Feel loved & 1.16 & 0.06 & 19.22 & $<.001$ \\
$\quad$ Listen & 1.32 & 0.08 & 15.76 & $<.001$ \\
Interested/concerned & 1.37 & 0.07 & 18.43 & $<.001$ \\
Psychological distress & & & & \\
Depressed & 1 & & & $<.001$ \\
Nervous & 0.97 & 0.04 & 27.36 & $<.001$ \\
Restless/fidgety & 1.07 & 0.04 & 25.67 & $<.001$ \\
$\quad$ Hopeless & 0.88 & 0.04 & 24.09 & $<.001$ \\
Worthless & 0.83 & 0.05 & 16.96 & $<.001$ \\
$\quad$ Effort & 0.77 & 0.04 & 18.34 & $<.001$ \\
$\quad$ Blue & 1.04 & 0.05 & 22.37 & \\
Structural model & & & & \\
Psychological distress & -0.26 & 0.06 & -0.37 & \\
\hline
\end{tabular}

characteristics of African American men from the NSAL have been reported elsewhere (Lincoln et al., 2011; Watkins et al., 2011), so the current study focuses on using the NSAL to test the conceptual model that we built using the Churches study with the aim of illuminating the effects of nonspousal family support on psychological distress for older, church-going African American men.

Based on our qualitative findings from the Churches data, we identified six factors (i.e., help, communication, closeness, feeling loved, listening, and expressing interests/concern) that were associated with the nonspousal family support experiences of older, church-going African American men. When we tested this conceptual model, quantitatively, we determined a good fit of the data to the hypothesized conceptual structure (Figure 2). The CFI was .96 , the TLI was .96 , the RMSEA is .05 , with a $90 \%$ confidence interval of .04 to .07 , and the SRMR was .04. All four of these values indicate a good fit of our conceptual model from the Churches data onto the items selected from the NSAL (Hu \& Bentler, 1999). Additionally, all items from the NSAL for both psychological distress and nonspousal family support were loaded and were found to be statistically significant $(p<.05)$ on the theorized latent variables, and no modifications were warranted based on the values calculated (Table 4). We then tested the effect of the latent, nonspousal social support variable on psychological distress and found that nonspousal family support is associated with fewer psychological distress symptoms $(\beta=-.26, p<.001)$. Furthermore, in both our qualitative and quantitative sample results, nonspousal family support was protective against psychological distress for older, church-going African American men.

\section{Integration of Qualitative and Quantitative Findings}

The point of interface for this exploratory sequential design using existing data sources occurred in between the qualitative analysis phase and the quantitative item-mapping phase of the study. Table 5 is a joint data display of this interface. First, by using the Churches study to conduct an in-depth analysis of the role of nonspousal family support on the psychological 


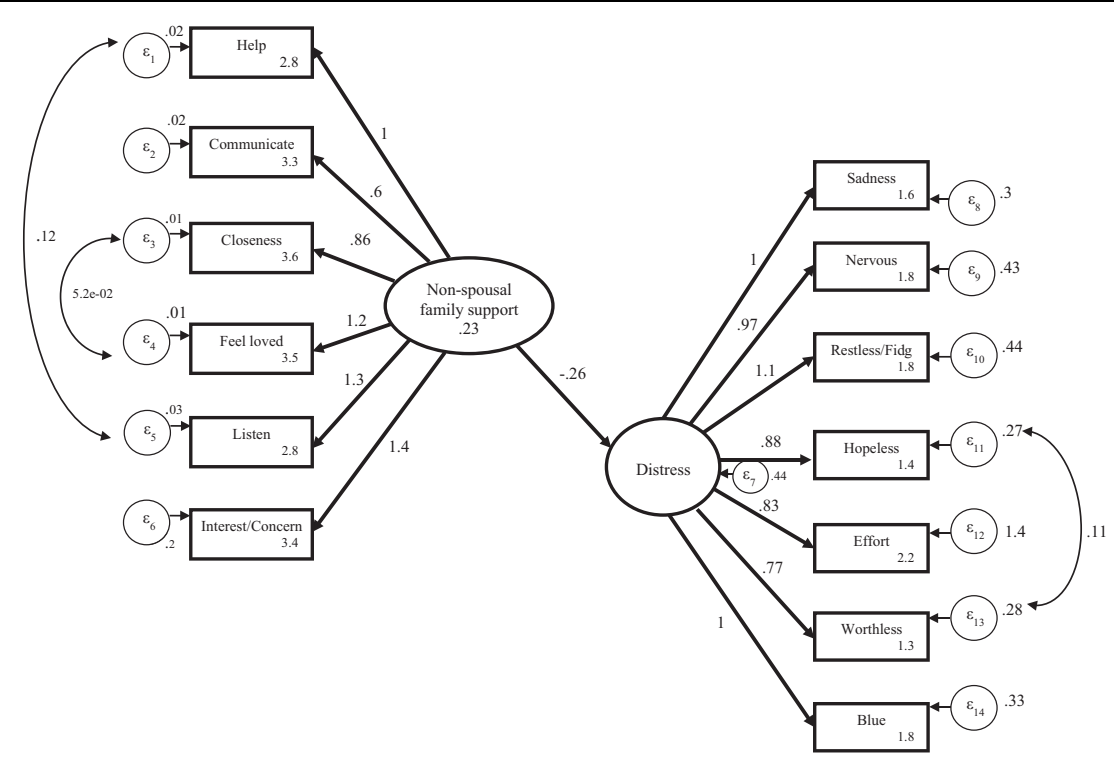

Figure 2. Confirmatory factor analysis model fit for nonspousal family support and psychological distress.

distress of older, African American men, we were able to develop a conceptual model that frames the social and cultural factors influencing nonspousal family support for older, churchgoing African American men. Next, the themes and subthemes derived from the Churches study were mapped onto items from the NSAL that described nonspousal family support.

Mapping was achieved by first creating a data mapping and triangulation table in which we listed concepts from the Churches study data related to nonspousal family support in one column of the table. Then in the adjoining column of this data mapping and triangulation table we listed potential items (questions and response options) from the NSAL that were related to nonspousal family support. Next, a three-person team from our group held a series of meetings to rate how well the qualitative concepts (derived from the Churches study themes and subthemes) mapped onto our proposed quantitative concepts (derived from the NSAL questionnaire). This process was performed iteratively, and involved closely examining the qualitative concepts, vetting the matching NSAL questionnaire item, then returning to the qualitative data for support and confirmation for which qualitative concepts mapped well onto the quantitative items. Disagreements among the three-person team were thoroughly discussed and resolved. The final six-factor loadings for nonspousal family support are the result of the team's agreement about which NSAL items best represented the Churches study concepts.

\section{Discussion}

The purpose of this study was to understand family support that extends beyond that of spouses and female partners (i.e., nonspousal) for church-going, African American men 50 years and older. This topic is important because of the role that female partners play in the health and health behaviors of men (Watkins, Abelson, \& Jefferson, 2013), as well as the role of the church in helping frame aging African American men's ideas for how they define family and who they 


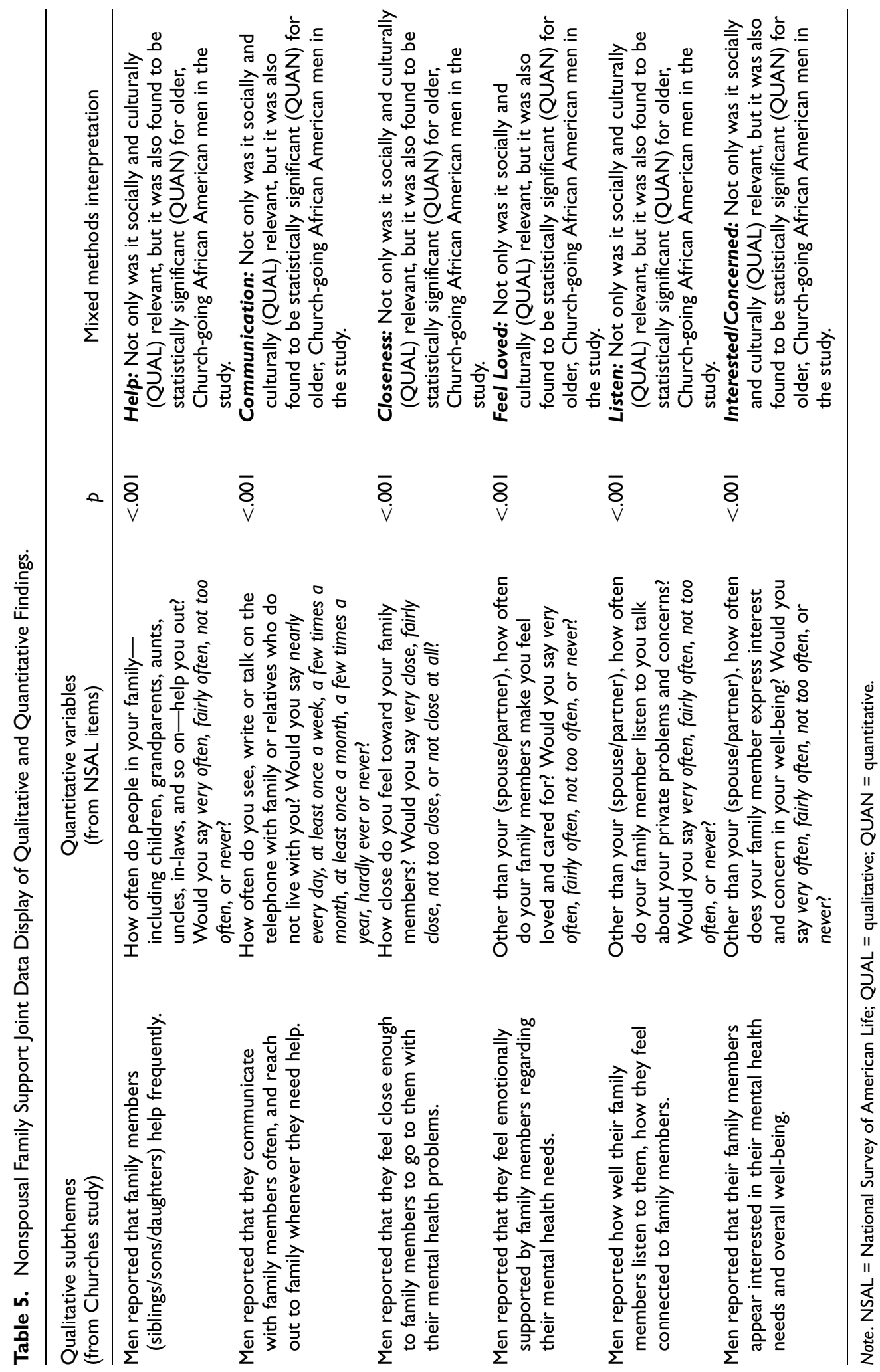


should seek when they experience mental health problems. Previous studies have underscored the importance of black churches in providing support for aging African Americans, but due to the way women are socialized to engage in social support, we were most interested in exploring how older, church-going men are socialized, as well as how they perceive the role of their family in offering support. We used a local qualitative study and a national quantitative study to deepen our understanding of this phenomenon. The modified exploratory sequential design employed in this mixed methods study using existing data helped acquire depth and breadth about the nonspousal family support experiences and mental health outcomes of older, churchgoing African American men within their social and cultural contexts.

From our analysis of the qualitative data, we found that (beyond their spouses and female partners) older, church-going African American men most often sought support for and refuge from their distress from their siblings and children. This finding suggests that as men age, they are more likely to consult their immediate family members regarding matters involving their health. Though our primary goal for this study was to deepen our understanding of the ways in which men perceive and receive social support from their family members (outside of the support they receive from their spouses and female partners) the majority of the focus group participants did discuss the important roles that their wives and female partners have in their mental health and well-being. With the exception of caregiving for mental illness (e.g., dementia, schizophrenia), the literature on support for more general mental health concerns (e.g., stress, distress) for men from their spouses and female partners is limited. This understudied research topic may speak to an area of study that needs further inquiry.

Our qualitative findings helped us identify a set of characteristics that older, church-going African American men found helpful from members of their nonspousal family support networks. These characteristics are consistent with previous literature framing the kind of characteristics and behaviors African American men prefer from concerned family members (Chatters et al., 2015). Using these six characteristics to create the latent variable "nonspousal family support" was beneficial in confirming the protective factors of this type of support in reducing psychological distress for older, church-going African American men. Our quantitative findings suggested that the six characteristics we identified from the qualitative findings (i.e., help, communication, closeness, feeling loved, listening, and expressing interests/concern) were a good fit for our latent variable, nonspousal family support. Likewise, our quantitative analysis suggested that nonspousal family support was inversely related to distress for older, church-going African American men. This finding is aligned with those of previous studies (Chatters et al., 2015; Ward \& Besson, 2012). However, previous studies often included spouses and other female partners in their analysis, which is not what we included in our analysis. Specifically, we found that the role of nonspousal support networks is also very important to the mental health and well-being of older African American men. Furthermore, this may be especially true for men who may have outlived their spouses and partners, were never married, or live alone.

Psychological distress was selected as the outcome for this study because stress and psychological distress have been found to capture a clearer description of the mental health experiences of African American men (Watkins, 2012a; Watkins \& Neighbors, 2007), oftentimes over and above the prevalence rates of clinical depression (Ward \& Besson, 2012). Given the distress that African American men may experience over their lifetime, the findings from this study are helpful in expanding our current understanding about the types of family support that may be useful for older, church-going African American men. Though the church provides a welcoming and supportive setting for many African American men as they age, we found that the relationships maintained outside of the church (both spousal and nonspousal) remain strong indicators for the way African American define themselves in terms of their sense of belonging, as well as how 
they situate themselves within the processes used to deal with mental health challenges, should they arise.

\section{Limitations}

Despite the contributions this study makes to the influence of nonspousal family support on the psychological distress of older, church-going African American men, it is not without its limitations. For example, although there are strengths in the design of this study, weaknesses exist that the reader should note while interpreting the findings. First, our analysis of the qualitative data from the Churches study is likely a reflection of our study team's reflexive approaches to the family support characteristics that are germane to our personal and professional lives. The study team consisted of five women from different racial, ethnic, and religious backgrounds, with no members of the team holding a membership in any of the churches from this study. Therein, we acknowledge that the qualitative phase of our mixed methods study may look very different had another team of researchers conducted the analysis.

Second, though we were successful in implementing an exploratory sequential design using existing data sources in this study, the mapping of existing qualitative concepts onto existing quantitative variables is still evolving and not without its limitations. Our review of previous studies suggests that existing data sources are usually used at the beginning (or for the first single-method phase) of a mixed methods study. However, as qualitative and quantitative data sources become more robust and sophisticated, the potential for implementing entire mixed methods studies using data that were previously collected for different purposes is promising (Watkins \& Gioia, 2015). Our use of an existing qualitative data source (the Churches study) to build a conceptual model and then using the NSAL (an existing quantitative data source) was a unique opportunity to capitalize on comprehensive and expansive measures of nonspousal family support for older, church-going African American men. Our integration of the qualitative and quantitative data was an attempt to make connects between two data sources with different original purposes. Though this was an innovative use of existing data, there are still limitations associated with using existing data sources for purposes beyond that of the original studies.

Finally, we acknowledge that our study was focused on the nonspousal family support experiences of church-going African American men, thus, not speaking to the experiences of non-church-going African American men. The implications for this exclusion are important to note, as older men, in general, tend to require more support for their health and daily living (Watkins, 2012a). So not being connected to a church or other social network as they age may exacerbate poor mental health for African American men. Despite this, and the other aforementioned limitations, the findings from this mixed methods study offers an innovative model for how two different data sources with two paradigm foci can be integrated to expand on the depth and breadth of the current discourse around the role of nonspousal family support in the mental health of older, church-going African American men.

\section{Implications}

The findings from this study have implications for future research topics, methods, and interventions. It is noteworthy to underscore that despite our goal to uncover characteristics of nonspousal family support, the majority of the men identified spouses and female partners as their primary support persons for when they are dealing with distress. This finding has implications for the role of women in the mental health decisions of men, which is a limited topic that has been addressed sparsely in previous research (Watkins, Abelson, \& Jefferson, 2013). Future studies should expound on the role of women in men's mental health, beyond the role often 
acquired by women as the caregiver of men with chronic disease and severe mental illness. Future studies should also expand on the current scholarship in this understudied area by crossreferencing data from men and female partners about the mental health and well-being of the men. Furthermore, this topic would also benefit from deeper inquiry into the similarities and differences among the various types of support African American men receive from their family, church, community networks, and their health care providers.

As for this study's implications for future interventions, programs that target African American men need a culturally sensitive, gender-specific approach that specifically addresses the unique characteristics of this population (Aronson, Whitehead, \& Baber, 2003; Watkins, Green, Goodson, Guidry, \& Stanley, 2007). Due to the risks associated with poor health and well-being, multidisciplinary interventions designed to address the intersection of these various health determinants are especially needed (Courtenay, 2000; Watkins, 2012a). Courtenay (2003) noted that the development of multidisciplinary methods to study men's health will require addressing the various health determinants involved and the disciplinary differences in outcome measures, population studies, methodologies applied, and rigor of program evaluations. These requirements will be especially relevant for work with older African American men.

With regard to the implications of this study for expanding research methods, use of qualitative and quantitative approaches promises to bridge the explanatory gap that exists between aggregated outcomes and experiences regarding the phenomenon of interest. Accordingly, the current mixed methods study explores issues relevant to the interpretive context within which the social and cultural context of psychological distress among older African American men takes place. In addition, mixed methods research will contribute to the development and integration of qualitative and quantitative approaches that provide the best models for how to comprehensively represent qualitative data involving inductive exploration alongside deductive examinations of the hypothesis-testing relationships found in quantitative approaches.

Using mixed methods to study the nonspousal family support of older, church-going African American men lends itself to truly capitalizing on what each of the single methods (qualitative and quantitative) can offer for the purposes of exploration and discovery in this understudied area. For instance, the lack of research on the social support networks of older African American men who experience psychological distress means that this area is in need of further inquiry into the social and cultural experiences of this unique subgroup of African American men. Qualitative methods offer opportunities to dig deeper into not just what older church-going African American men experience but also how they experience it, described in their own words. On the contrary, quantitative methods offer a chance to ascertain prevalence rates and the scope of the outcomes at the broader level. Nationally representative data on the mental health and well-being of older African American men are limited, particularly when compared to existing national data on White men. However, the NSAL is one of the largest mental health surveys to sample African Americans, thus offering our team a chance to not only examine the breadth of psychological distress and nonspousal family support among older, church-going African American men but also use qualitative data to build a conceptual model that we could test using a representative sample of older, church-going African American men from the NSAL. This innovative use of mixed methods with existing qualitative and quantitative data expands our topic area, as well as the possibilities for more creative ways of analyzing and integrating other existing qualitative and quantitative data sources. The current study provided an opportunity for us to build on the work of our mixed methods predecessors by taking our definition of mixed methods to the next level. 


\section{Conclusion}

It is often assumed that, by virtue of their church affiliation, older African American men are more resilient to their life stressors and emerge with better mental health outcomes compared to their younger counterparts. However, under certain circumstances, churches, alone, may not provide the type of protection needed to improve and maintain positive mental health outcomes for older African American men. Though some studies support this (Chatters et al., 2015; Dessio et al., 2004; Ward \& Besson, 2012; Watkins, 2012a), others assert that in the absence of family, the church can provide a familial grounding for African Americans that results in positive health and well-being overall. To further examine this assertion, this study used existing data sources to examine how nonspousal family support influences psychological distress among older, church-going African American men.

\section{Acknowledgements}

The authors would like to acknowledge Babe Kawaii-Bogue for her assistance with the preliminary data analysis associated with this article.

\section{Declaration of Conflicting Interests}

The author(s) declared no potential conflicts of interest with respect to the research, authorship, and/or publication of this article.

\section{Funding}

The author(s) disclosed receipt of the following financial support for the research, authorship, and/or publication of this article: The data collection for this study was supported by the Program for Positive Aging in the Department of Psychiatry at the University of Michigan, and the original study was titled "Attitudes, perceptions, and beliefs pertaining to mental health, depression, and depression care of elder African American church attendees" (Principal Investigator: Helen C. Kales, MD, UM Department of Psychiatry). The data analysis for this study was supported by a pilot grant from the National Institutes of Health, 5P30 AG015281, and the Michigan Center for Urban African American Aging Research, titled "Depressive Symptoms among Aging African American Men: A mixed methods study of social and cultural contexts" (Principal Investigator: Daphne C. Watkins, PhD, UM School of Social Work and Department of Psychiatry).

\section{References}

Akaike, H. (1974). A new look at the statistical model identification. IEEE Transactions on Automatic Control, 19, 716-723.

Anderson, E. A., Kohler, J. K., \& Letiecq, B. L. (2005). Predictors of depression among low-income, nonresidential fathers. Journal of Family Issues, 26, 547-567.

Aronson, R. E., Whitehead, T. L., \& Baber, W. L. (2003). Challenges to masculine transformation among low-income African American males. American Journal of Public Health, 93, 732-741.

Bazeley, P. (2009). Integrating data analyses in mixed methods research. Journal of Mixed Methods Research, 3(3), 203-206.

Bentler, P. M. (1990). Comparative fit indexes in structural models. Psychological Bulletin, 107(2), 238-246.

Boduszek, D., Shevlin, M., Mallett, J., Hyland, P., \& O'Kane, D. (2012). Dimensionality and construct validity of the Rosenberg Self-Esteem Scale within a sample of recidivistic prisoners. Journal of Criminal Psychology, 2(1), 19-25. 
Buttram, M. E., \& Kurtz, S. P. (2015). A mixed methods study of health and social disparities among substance-using African American/Black men who have sex with men. Journal of Racial and Ethnic Health Disparities, 2(1), 1-10.

Caldwell, C. H., Antonakos, C., Tsuchiya, K., Assari, S., \& De Loney, E. H. (2013). Masculinity as a moderator of discrimination and parenting on depressive symptoms and drinking among nonresident African American fathers. Psychology of Men \& Masculinity, 14, 47-58.

Chatters, L. M., Taylor, R. J., Woodward, A. T., \& Nicklett, E. J. (2015). Social support from church and family members and depressive symptoms among older African Americans. American Journal of Geriatric Psychiatry, 23, 559-567.

Compton, M. T., Thompson, N. J., \& Kaslow, N. J. (2005). Social environment factors associated with suicide attempt among low-income African Americans: The protective role of family relationships and social support. Social Psychiatry \& Psychiatric Epidemiology, 40, 175-185.

Conner, K. O., Copeland, V. C., Grote, N. K., Rosen, D., Albert, S., McMurray, M. L., . . . Koeske, G. (2010). Barriers to treatment and culturally endorsed coping strategies among depressed AfricanAmerican older adults. Aging \& Mental Health, 14, 971-983.

Cooper, J. N., \& Hall, J. (2014). Understanding black male student athletes' experiences at a historically black college/university: A mixed methods approach. Journal of Mixed Methods Research. Advanced online publication. doi:10.1177/155868981455845

Creswell, J. W., \& Tashakkori, A. (2007). Developing publishable mixed methods manuscripts. Journal of Mixed Methods Research, 1(2): 107-111.

Creswell, J. W. (2015). A concise introduction to mixed methods research. Thousand Oaks, CA: Sage.

Creswell, J. W., \& Plano Clark, V. L. (2011). Designing and conducting mixed methods research (2nd ed.). Thousand Oaks, CA: Sage.

Courtenay, W. H. (2000). Constructions of masculinity and their influence on men's well-being: A theory of gender and health. Social Science and Medicine, 50, 1385-1401.

Courtenay, W. H. (2003). Key determinants of the health and well-being of men and boys. International Journal of Men's Health, 2(1), 1-30.

Curry, L., \& Nunez-Smith, M. (2015). Mixed methods in health sciences research: A practical primer. Thousand Oaks, CA: Sage.

Dessio, W., Wade, C., Chao, M., Kronenberg, F., Cushman, L. E., \& Kalmuss, D. (2004). Religion, spirituality, and healthcare choices of African-American women: Results of a national survey. Ethnicity \& Disease, 14, 189-197.

Ellis, K., Caldwell, C. H., Assari, S., \& De Loney, E. H. (2014). Nonresident African American fathers' influence on sons' exercise intentions in the Fathers \& Sons Program. American Journal of Health Promotion, 29(2), 89-98.

Fernald, D. H., \& Duclos, C. W. (2005). Enhance your team-based qualitative research. Annals of Family Medicine, 3, 360-364.

Gaines, J. S. (2007). Social correlates of psychological distress among adult African American males. Journal of Black Studies, 37, 827-858

Grinnell, R. M., Jr., \& Unrau, Y. A. (Eds.). (2014). Social work research and evaluation (10th ed.). New York, NY: Oxford University Press.

Guest, G., \& MacQueen, K. (2008). Reevaluating guidelines for qualitative research. In G. Guest \& K. MacQueen (Eds.), Handbook for team-based qualitative research (pp. 205-226). Lanham, MD: AltaMira Press.

Haight, W., \& Bidwell, L. N. (2015). Mixed methods research for social work. Chicago, IL: Lyceum Books.

Hamilton, J. B., Moore, C. E., Powe, B. D., Agarwal, M., \& Martin, P. (2010). Perceptions of support among older African American cancer survivors. Oncology Nursing Forum, 37, 484-493.

Harris, L. (2013). Feel the heat! The unrelenting challenge of young black male unemployment: Policies and practices that could make a difference. Retrieved from http://www.clasp.org/resources-andpublications/files/Feel-the-Heat_Web.pdf

Hesse-Biber, S. N. (2010). Mixed methods research: Merging theory with practice. New York, NY: Guilford. 
Hoyert, D. L., \& Xu, J. (2012). Deaths: Preliminary data for 2011. National Vital Statistics Report, 61(6), $1-65$.

Hu, L.-T., \& Bentler, P. M. (1999). Cutoff criteria for fit indices in covariance structure analysis: Conventional criteria versus new alternatives. Structural Equation Modeling, 6, 1-55.

Hurt, T. R. (2012). Toward a deeper understanding of the meaning of marriage among Black men. Journal of Family Issues, 34, 859-884.

Jackson, J. S., Torres, M., Caldwell, C. H., Neighbors, H. W., Nesse, R. M., Taylor, R. J., . . Williams, D. R. (2004). The National Survey of American Life: A study of racial, ethnic and cultural influences on mental disorders and mental health. International Journal of Methods in Psychiatric Research, 13, 196-207.

Johnson, R. B., Onwuegbuzie, A. J., \& Turner, L. A. (2007). Toward a definition of mixed methods research. Journal of Mixed Methods Research, 1(2), 112-133.

Jöreskog, K. G., \& Sörbom, D. (1981). LISREL V: Analysis of linear structural relation-ships by maximum likelihood and least squares methods (Research Report 81-8). Uppsala, Sweden: University of Uppsala, Department of Statistics.

Kartalova-O'Doherty, Y., \& Doherty, D. T. (2009). Satisfied careers of persons with enduring mental illness: Who and why? International Journal of Social Psychiatry, 55, 257-271.

Kessler, R. C., Green, J. G., Gruber, M. J., Sampson, N. A., Bromet, E., Cuitan, M., . . Zaslavsky, A. M. (2010). Screening for serious mental illness in the general population with the K6 screening scale: Results from the WHO World Mental Health (WMH) survey initiative. International Journal of Methods in Psychiatric Research, 19(Suppl. 1), 4-22.

Krause, N. (2006). Exploring the stress-buffering effects of church-based and secular social support on self-rated health in late life. Journals of Gerontology, Series B: Psychological Sciences \& Social Sciences, 61(1), S35-S43.

Leech, N. L., \& Onwuegbuzie, A. J. (2007). An array of qualitative data analysis tools: A call for data analysis triangulation. School Psychology Quarterly, 22, 557-584.

Leech, N. L., \& Onwuegbuzie, A. J. (2008). Qualitative data analysis: A compendium of techniques and a framework for selection for school psychology research and beyond. School Psychology Quarterly, 23, 587-604.

Lincoln, K. D., Chatters, L. M., \& Taylor, R. J. (2003). Psychological distress among Black and White Americans: Differential effects of social support, negative interaction and personal control. Journal of Health and Social Behavior, 44, 390-407.

Lincoln, K. D., Taylor, R. J., Watkins, D. C., \& Chatters, L. M. (2011). Correlates of psychological distress and major depressive disorder among African American men. Research on Social Work Practice, 21, 278-288.

Littrell, J., \& Beck, E. (2001). Predictors of depression in a sample of African-American homeless men: Identifying effective coping strategies given varying levels of daily stressors. Community Mental Health Journal, 37, 15-29.

Mac an Ghaill, M. (1994). The making of men: Schooling, masculinities and sexualities. Buckingham, England: Open University Press.

National Center for Health Statistics. (1998). Health, United States, 1998 with socioeconomic and health chart book. Hyattsville, MD: Author.

Neighbors, H. W., Musick, M. A., \& Williams, D. R. (1998). The African American minister as a source of help for serious personal crises: Bridge or barrier to mental health care? Health Education \& Behavior, 25, 759-777.

Neighbors, H. W., Woodward, A. T., Bullard, K. M., Ford, B. C., Taylor, R. J., \& Jackson, J. S. (2008). Mental health service use among older African Americans: The National Survey of American Life. American Journal of Geriatric Psychiatry, 16, 948-956.

Niglas, K. (2007). Media review: Microsoft Office Excel spreadsheet software. Journal of Mixed Methods Research, 1(3), 297-299.

Padgett, D. K. (2008). Qualitative methods in social work research (Vol. 36). Thousand Oaks, CA: Sage. 
Pearlin, L. I. (1999). The stress process revisited: Reflections on concepts and their interrelationships. In C. Aneshensel \& J. Phelan (Eds.), Handbook of sociology of mental health (pp. 395-415). New York, NY: Kluwer Academic/Plenum.

Rosenfarb, I. S., Bellack, A. S., \& Aziz, N. (2006). Family interactions and the course of schizophrenia in African American and White patients. Journal of Abnormal Psychology, 115, 112-120. doi: 10.1037/0021-843X.115.1.112

Roy, K. M., \& Dyson, O. (2010). Making daddies into fathers: Community-based fatherhood programs and the construction of masculinities for low-income African American men. American Journal of Community Psychology, 45, 139-154.

Shellman, J., Granara, C., \& Rosengarten, G. (2011). Barriers to depression care for black older adults. Journal of Gerontological Nursing, 37, 13-17.

Sitgraves, C. (2008). The benefits of marriage for African-American men (Report No. 10). New York, NY: Institute for American Values. Retrieved from http://center.americanvalues.org

StataCorp. (2013). Stata Statistical Software: Release 13. College Station, TX: StataCorp.

Stockdale, M. S. (2002). Analyzing focus group data with spreadsheets. American Journal of Health Studies, 18, 55-60.

Swallow, V., Newton, J., \& Lottum, C. V. (2003). How to manage and display qualitative data using "Framework" and Microsoft ${ }^{\circ}$ Excel. Journal of Clinical Nursing, 12, 610-612.

Tang, T. S., Brown, M. B., Funnell, M. M., \& Anderson, R. M. (2008). Social support, quality of life, and self-care behaviors among African Americans with type 2 diabetes. Diabetes Educator, 34, 266-276.

Tashakkori, A., \& Teddlie, C. (2003). Handbook of mixed methods in social \& behavioral research. Thousand Oaks, CA: Sage.

Taylor, R. J., \& Chatters, L. M. (2011). Religious media use among African Americans, Black Caribbeans and Non-Hispanic Whites: Findings from the National Survey of American Life. Journal of African American Studies, 15, 433-454.

Taylor, R. J., Chatters, L. M., \& Jackson, J. S. (1997). Changes over time in support network involvement among Black Americans. In R. J. Taylor, J. S. Jackson, \& L. M. Chatters (Eds.), Family life in Black America (pp. 293-316). Thousand Oaks, CA: Sage.

Taylor, R. J., Chatters, L. M., \& Jackson, J. S. (2007). Religious and spiritual involvement among older African Americans, Caribbean blacks, and non-Hispanic whites: Findings from the National Survey of American Life. Journals of Gerontology, Series B: Psychological Sciences \& Social Sciences, 62, S238-S250.

Taylor, R. J., Ellison, C. G., Chatters, L. M., Levin, J. S., \& Lincoln, K. D. (2000). Mental health services in faith communities: The role of clergy in black churches. Social Work, 45(1), 73-87.

Taylor, R. J., Forsythe-Brown, I., Taylor, H. O., \& Chatters, L. M. (2014). Patterns of emotional social support and negative interactions among African American and Black Caribbean extended families. Journal of African American Studies, 18, 147-163.

Taylor-Powell, E., \& Renner, M. (2003). Analyzing qualitative data. Retrieved from http:// learningstore.uwex.edu/assets/pdfs/g3658-12.pdf

Tucker, L. R., \& Lewis, C. (1973). A reliability coefficient for maximum likelihood factor analysis. Psychometrika, 38, 1-10.

Ulin, P. R., Robinson, E. T., \& Tolley, E. E. (2005). Qualitative methods in public health: A field guide for applied research. San Francisco, CA: Jossey-Bass.

Ward, E. C., \& Besson, D. D. (2012). African American men's beliefs about mental illness, perceptions of stigma, and help-seeking barriers. Counseling Psychologist, 41, 359-391.

Watkins, D. C., \& Neighbors, H. W. (2007). An initial exploration of what "mental health" means to young Black men. Journal of Men's Health \& Gender, 4, 271-282.

Watkins, D. C. (2012a). Depression over the adult life course for African American men: Toward a framework for research and practice. American Journal of Men's Health, 6, 194-210.

Watkins, D. C. (2012b). Qualitative research: The importance of conducting research that doesn't "count." Health Promotion Practice, 13, 153-158. 
Watkins, D. C., Abelson, J. M., \& Jefferson, S. O. (2013). "Their depression is something different . . it would have to be": Findings from a qualitative study of Black women's perceptions of Black men's depression. American Journal of Men's Health, 7(4 Suppl.), 45S-57S.

Watkins, D. C., \& Gioia, D. (2015). Mixed methods research: Pocket guides to social work research series. New York, NY: Oxford University Press.

Watkins, D. C., Green, B. L., Goodson, P., Guidry, J., \& Stanley, C. A. (2007). Using focus groups to explore the stressful life events of Black college men. Journal of College Student Development, 48, 105-118.

Watkins, D. C., Hudson, D. L., Caldwell, C. H., Siefert, K., \& Jackson, J. S. (2011). Discrimination, mastery, and depressive symptoms among African American men. Research on Social Work Practice, $21,269-277$.

Watkins, D. C., \& Neighbors, H. W. (2012). Social determinants of depression and the black male experience. In H. M. Treadwell, C. Xanthos, \& K. B. Holden, K. B. (Ed), Social determinants of health among African-American men (pp. 39-62). San Francisco, CA: Jossey-Bass.

White, J. (2004). Toward a Black psychology. In R. Jones (Ed.), Black psychology (4th ed., pp. 5-16). Hampton, VA: Cobb \& Henry. 